Virtual Panorama Landing dan Take Off Bandara Adi Sumarmo Solo

\title{
VIRTUAL PANORAMA LANDING DAN TAKE OFF \\ BANDARA ADI SUMARMO SOLO
}

\author{
Nurcahyani Dewi Retnowati ${ }^{1}$, Muhammad Zainal Muttaqim ${ }^{2}$ \\ Program Studi Teknik Informatikna \\ Sekolah Tinggi Teknologi Adisutjipto \\ Jalan Janti Blok R Lanud Adisutjipto, Yogyakarta \\ 1ndewiret@gmail.com
}

\begin{abstract}
The development of information technology and lead to intense competition in all areas, many parties began implementing a strategy to improve services. Information obtained from various sources such as the Internet can make it easier to determine the state of a place or vehicle that will be addressed, but a lot of information from various sources, it only displays a static image that is not enough to describe the situation as a whole as well as the environment, it is necessary for the proper media for representing the information. One type of appropriate multimedia effective dam to provide information or a description of the location of these is to use virtual panoramic view. Not like a video that is merely one direction (forward grooved) virtual panoramic view is designed to allow the user to interact directly with the environment to crawl closer and more interactive. Final results from this aplication is a multimedia display that can be applied in any kind of media because using ActionScript for basic program so that it can be applied via online websites or interactive CDs or display advertising.
\end{abstract}

Keyword: Virtual panoramic view, Action Script

\begin{abstract}
Abstrak
Perkembangan teknologi dan informasi menimbulkan persaingan yang ketat di segala bidang, Banyak pihak mulai menerapkan strategi untuk meningkatkan layanan. Informasi yang didapat dari berbagai sumber semisal internet dapat memudahkan untuk mengetahui keadaan suatu tempat atau wahana yang akan dituju namun banyak informasi dari berbagai sumber tersebut hanya menampilkan gambar statis yang tidak cukup untuk menggambarkan secara kesuluruhan situasi maupun lingkungan tersebut, untuk itu diperlukan media yang tepat untuk mewakili informasi itu. Salah satu jenis multimedia yang tepat dan efektif untuk memberikan informasi gambaran lokasi atau tempat tersebut adalah dengan mengunakan virtual view panorama. Berbeda dengan video yang hanya bersifat satu arah (beralur maju) virtual view panorama dirancang untuk memungkinkan agar pengguna dapat berinteraksi secara langsung dengan lingkungan tersebut untuk menjelajah lebih dekat dan lebih interaktif. Hasil dari virtual view Panorama ini adalah berupa tampilan multimedia yang dapat diterapkan dalam berbagai media karena menggunakan basis ActionScript sehingga dapat diterapkan via online website maupun CD interaktif atau iklan display.
\end{abstract}

Kata kunci :Virtual view panorama, Action Script

JURNAL ANGKASA 


\section{Pendahuluan}

Pada jaman sekarang ini perkembangan teknologi dan informasi dapat mengakibatkan persaingan yang ketat di segala bidang. Banyak pihak mulai menerapkan strategi untuk meningkatkan layanan mereka. Informasi yang didapat dari berbagai sumber semisal internet dapat memudahkan untuk mengetahui keadaan suatu tempat atau wahana yang akan dituju namun banyak informasi dari berbagai sumber tersebut hanya menampilkan gambar statis yang tidak cukup untuk menggambarkan secara keseluruhan situasi maupun lingkungan tersebut, untuk itu diperlukan media yang tepat untuk mewakili informasi itu. Salah satu jenis multimedia yang tepat dam efektif untuk memberikan informasi gambaran lokasi atau tempat tersebut adalah dengan mengunakan virtual view panorama. Virtual view Panorama ini akan menciptakan sebuah adegan yang lengkap sebagai gambar tunggal, seperti yang terlihat ketika berputar pada posisi ditengah pada suatu tempat.Hasil dari virtual view Panorama ini adalah berupa tampilan multimedia yang dapat diterapkan dalam berbagai media karena menggunakan basis ActionScript sehingga dapat diterapkan via online website maupun $C D$ interactive. Diharapkan penerapan virtual view pada landing \& take off pesawat dapat menampilkan sebuah objek foto atau gambar dengan sudut pandangan yang lebih luas.

\section{Landasan Teori}

Penelitian ini berfungsi untuk memanfaatkan teknologi virtual untuk menampilkan informasi secara detail dan lengkap dengan sudut pandang 360 derajat.

\subsection{Multimedia Interaktif}

Multimedia interaktif adalah suatu multimedia yang dilengkapi dengan alat pengontrol yang dapat dioperasikan oleh pengguna, sehingga pengguna dapat memilih apa yang dikehendaki untuk proses selanjutnya.

\subsection{Objek Virtual}

Dalam optik, gambar virtual adalah gambar terbentuk ketika sinar keluar dari titik pada objek yang berbeda. Gambar dengan jelasseperti terletak pada titik yang berbeda.

\subsection{Virtual Tour}

Virtual Tour adalah simulasi dari lokasi yang ada, biasanya terdiri dari urutan video atau gambar diam, juga dapat menggunakan unsur-unsur multimedia lainnya seperti efek suara, musik, narasi, dan teks. 


\subsection{Panorama Photo}

Sebuah gambar menunjukkan bidang luas aproksimasi, atau lebih besar dari sudut mata manusia atau sekitar $160^{\circ}-75^{\circ}$ dapat disebut panorama photo.

\subsection{ActionScript}

ActionScript adalah bahasa pemrograman ActionScript merupakan bahasa pemrograman berorientasi objek didasarkan pada ECMAScript-standar digunakan dalam pengembangan situs web dan perangkat lunak menggunakan platform Adobe Flash Player.

\section{Desain Dan Perancangan Sistem}

\subsection{Analisis Kebutuhan Sistem}

\subsubsection{Kebutuhan Fungsional}

Virtual view landing\&take off pesawat ini harus bisa memberikan informasi yang sesuai dengan pembahasan yang menarik dalam penyajiannya. Fungsi dari aplikasi virtual view ini adalah menampilkan objek landing \& take off pesawat secara luas yaitu dengan memanfaatkan gambar panorama photo. Gambar yang ditampilkan memiliki sudut pandang yang lebih luas dari pada foto biasa.

\subsection{Perancangan Sistem}

\subsubsection{Merancang Konsep}

Konsep yang akan diterapkan pada virtual view landing dan take off pesawat ini adalah memberikan informasi objek grafis atau gambar dengan sudut lebar atau wide angle, artinya bahwa aplikasi ini memberikan informasi gambar dengan view secara lebar dan luas tentang gambaran landing dan take off pesawat.

\subsubsection{Merancang grafik}

Dalam merancang grafik diperlukan perpaduan dan kesesuaian warna serta tata letak objek virtual view agar aplikasi tampak menarik. Berikut contoh tampilannya :

$\begin{array}{ll}\text { Resolusi Layar } & : 1024 \times 575 \text { Pixel, } 24 \text { fps } \\ \text { Warna Background } & \text { : Biru dan kombinasi putih } \\ \text { Player } & : \text { Flash Player } 9 \\ \text { Actionscript } & : \text { Actionscript } 3.0\end{array}$




\begin{tabular}{|c|c|}
\hline Judul & \\
\hline \hline \multicolumn{2}{|c|}{ Panorama Photo } \\
\\
\hline Teks \\
\hline
\end{tabular}

\subsubsection{Diagram Proses Perancangan Aplikasi}

Proses awal perancangan aplikasi virtual view ini adalah dengan melakukan pengambilan gambar terhadap objek, yang akan dijadikan sebuah panorama photo. Setelah melakukan pengambilan gambar pada objek kemudian proses selanjutnya adalah pembuatan gambar panorama photo menggunakan teknik Photomerge pada software Adobe Photoshop. Setelah gambar panorama photo sudah jadi, proses selanjutnya adalah pembuatan aplikasi virtual view di software Adobe Flash.

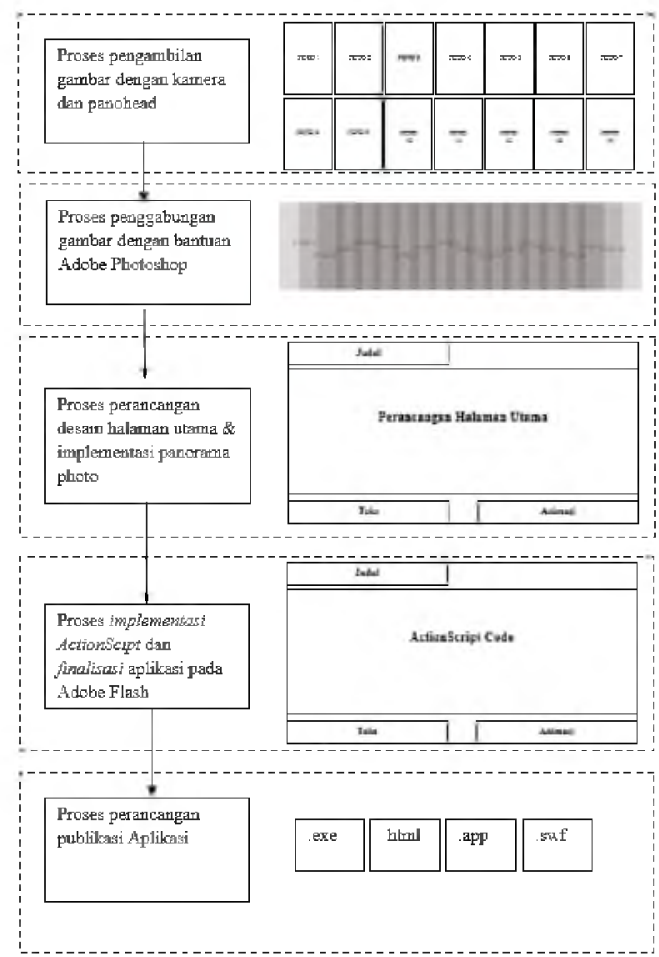

Gambar 2. Diagram Proses Perancangan Aplikasi 


\section{Implementasi Dan Analisis Sistem}

\subsection{Implementasi Pengambilan Gambar}

Untuk menghasilkan sebuah panorama photo diperlukan tahapan pengambilan gambar pada objek di lokasi. Pengambilan gambar memanfaatkan sebuah DSLR Canon EOS 1100D lensa kit 18 - 55 mm, serta memanfaatkan tripod dan panohead untuk memudahkan dalam pengambilan gambar agar posisi kamera tetap statis dengan pengaturan kamera yang sudah ditentukan.

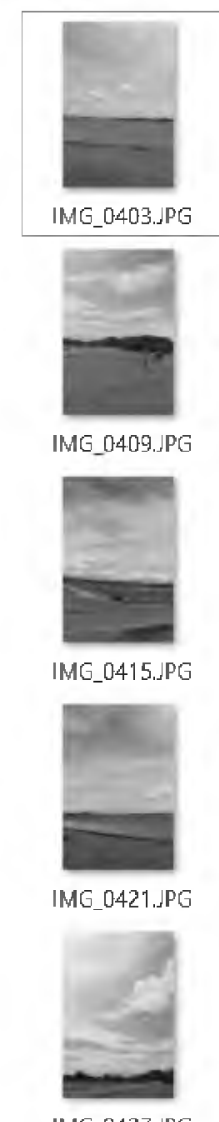

IMG_[0427.JPG
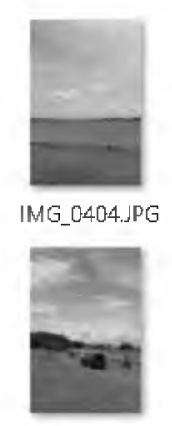

IMG_0410.JPG

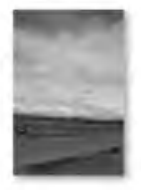

|MG_0416.JPG

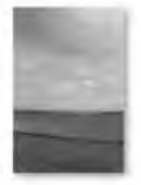

IMG_0422,JPG

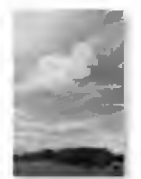

IMG_0428.JPG
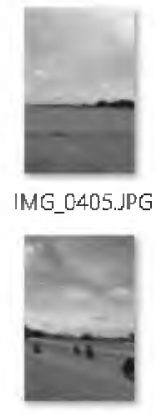

IMG_Q-41 1.JPG
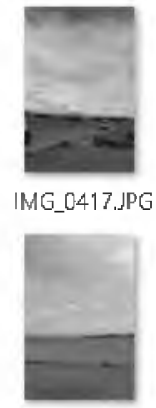

IMG_0.423.JPG

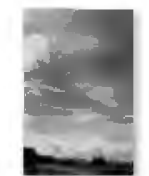

IMG_0-429.JPG

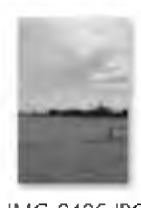

IMG_0406.JPG

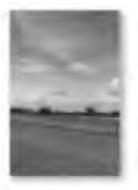

IMG_0412.JPG

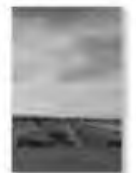

IMG_0478.JPG

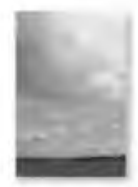

IMG_0424.JPG

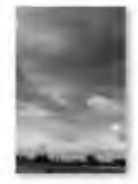

IMG_[030.JPG
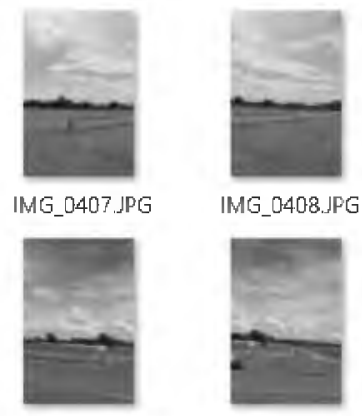

IMG_0413.JPG
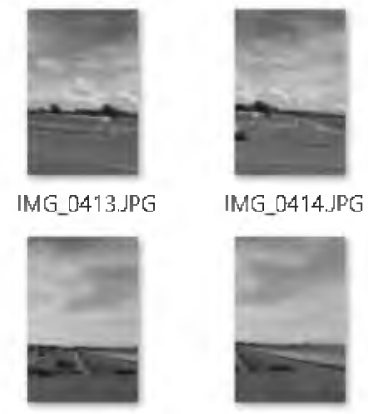

IMG_0419.JPG
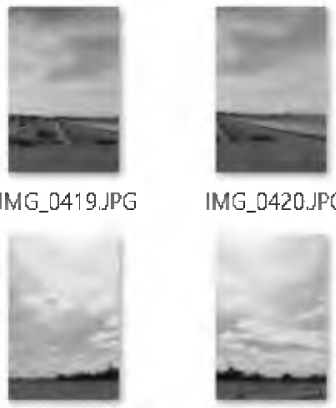

ING_0425.JPG

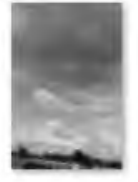

IMG_[431.JPG
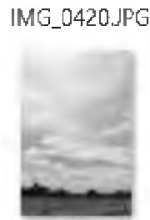

IMG_0426.JPG

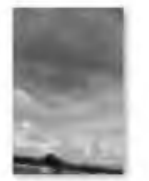

IMG_[432.JPG

Gambar 3. Pengambilan Gambar Objek Virtual View

\subsection{Implementasi Penggabungan Gambar}

Untuk membuat sebuah gambar panorama photo memerlukan gambar yang cukup banyak dengan teknik pengambilan gambar secara berurutan. Gambar-gambar ini kemudian diolah menggunakan software Adobe Photoshop CS5 dengan teknik penggabungan atau merge.Hasil dari penggabungan ini adalah sebuah gambar panorama photo. 


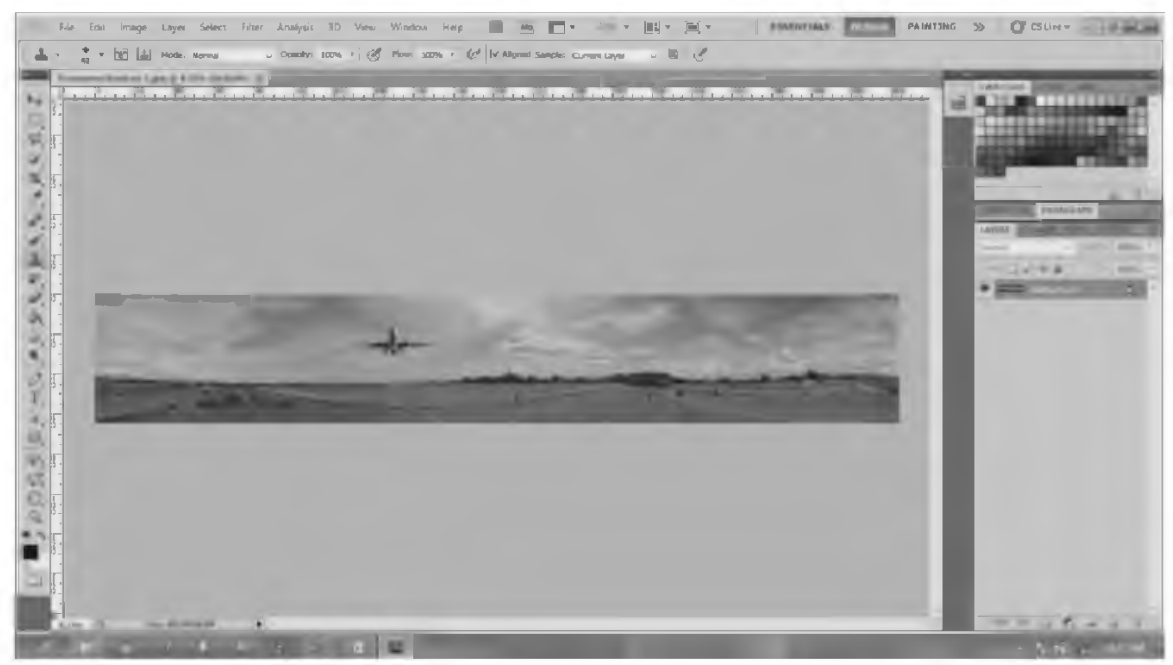

Gambar 4. hasil Penggabungan Gambar

\subsection{Implementasi Perancangan Halaman Utama}

Halaman utama aplikasi virtual view ini dirancang atau dibuat semenarik mungkin, karena merupakan antar muka utama atau halaman utama yang berhubungan langsung dengan pengguna

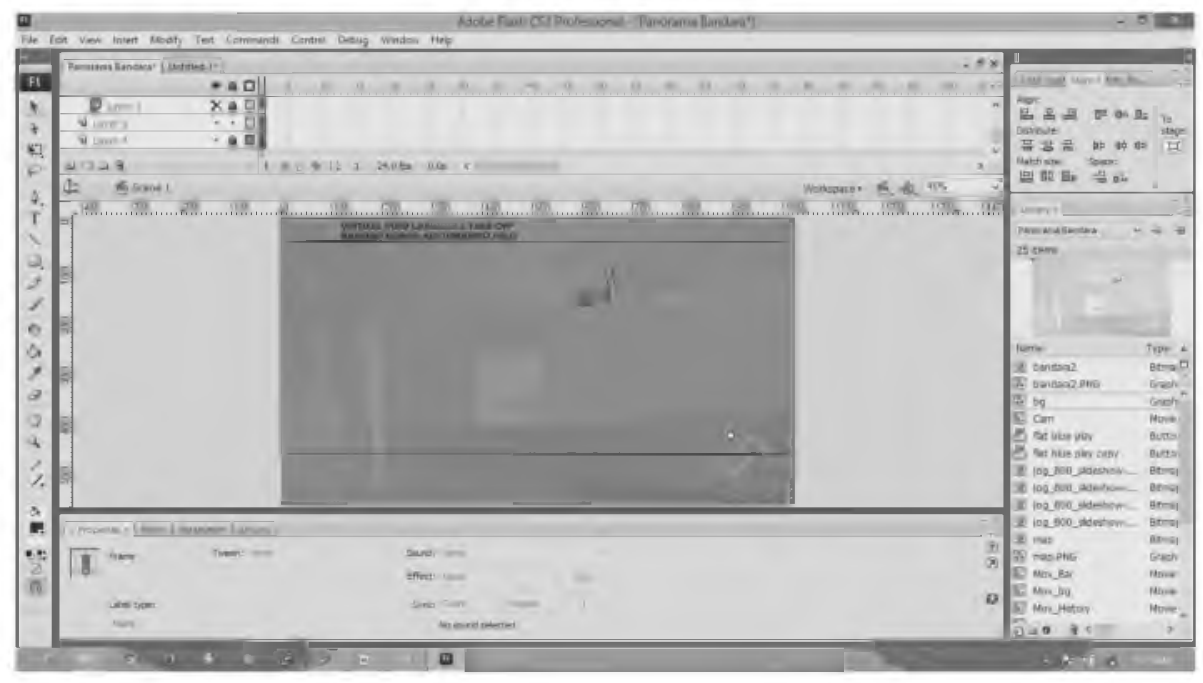

Gambar 5. Halaman Utama

\subsection{Implementasi Panorama Photo}

Tampilan virtual view landing dan take off pesawat merupakan gambar panorama photo dari landing dan take off pesawat di Bandar Udara Adi Sumarmo Solo. Gambar diambil dari 
segala arah secara horizontal dengan sudut pengambilan gambar yang luas. Selanjutnya gambar tersebut diolah menjadi sebuah gambar panorama photo.

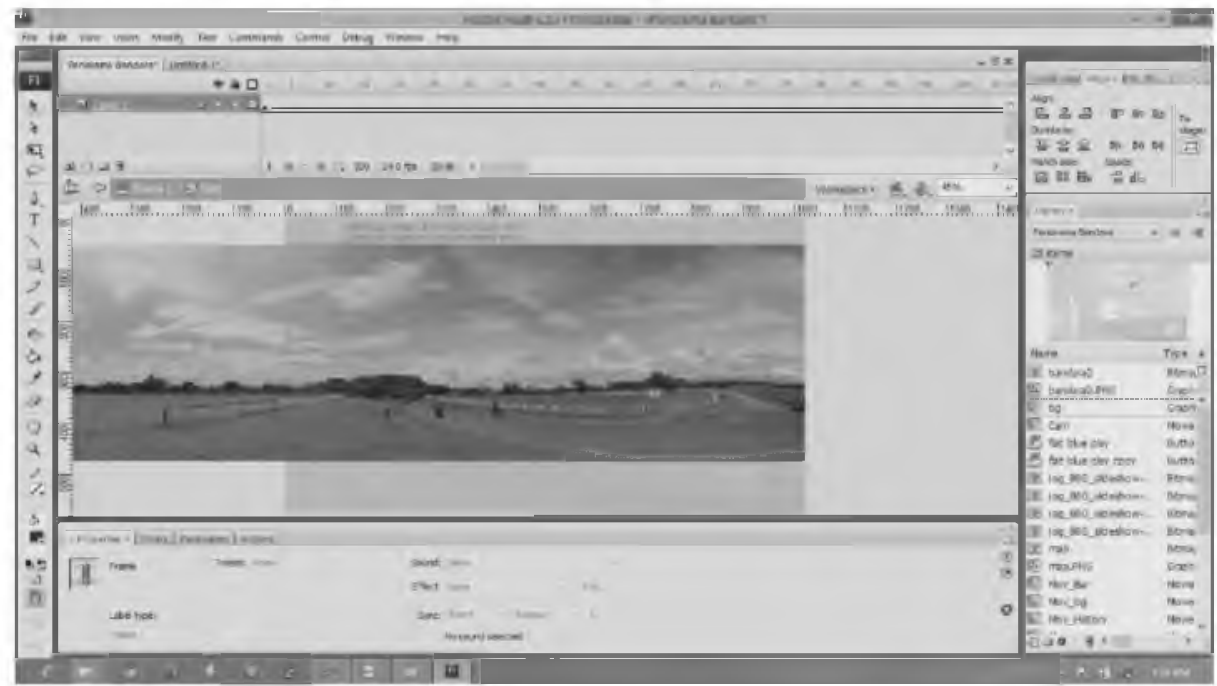

Gambar 6. Implementasi Panorama Photo

\subsection{Implementasi ActionScript}

Dalam perancangan virtual view ini menggunakan perintah Action Script dalam adobe flash. Action Script merupakan bahasa programming yang digunakan oleh Adobe Flash, dalam Action Script ini dapat melakukan beberapa fungsi dan perintah.

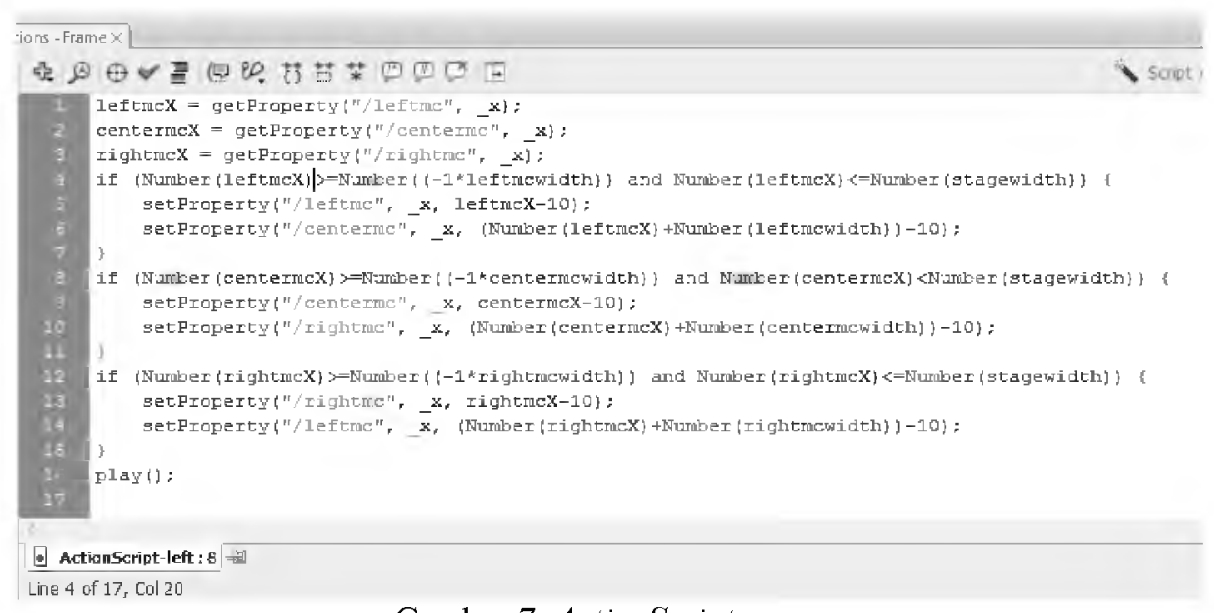

Gambar 7. ActionScript

\subsection{Implementasi Publish Sistem}

Setelah tahap perancangan aplikasi virtual view selesai selanjutnya adalah tahap publih file dokumen flash (Fla) menjadi File Swf dan Exe. 


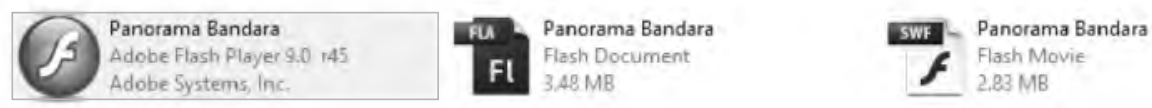

Gambar 8. File Publikasi

\subsection{Uji Coba Aplikasi Virtual View}

Tahap uji coba aplikasi virtual view landing dan take off pesawat dilakukan bertujuan untuk mengevaluasi atau mengetahui beberapa kekurangan yang ada pada aplikasi virtual view ini. Uji coba dilakukan dengan mengoperasikan seluruh fungsi navigasi yang ada pada aplikasi view landing, tampilan gambar dan animasi serta kompatibilitas dengan perangkat komputer yang digunakan.

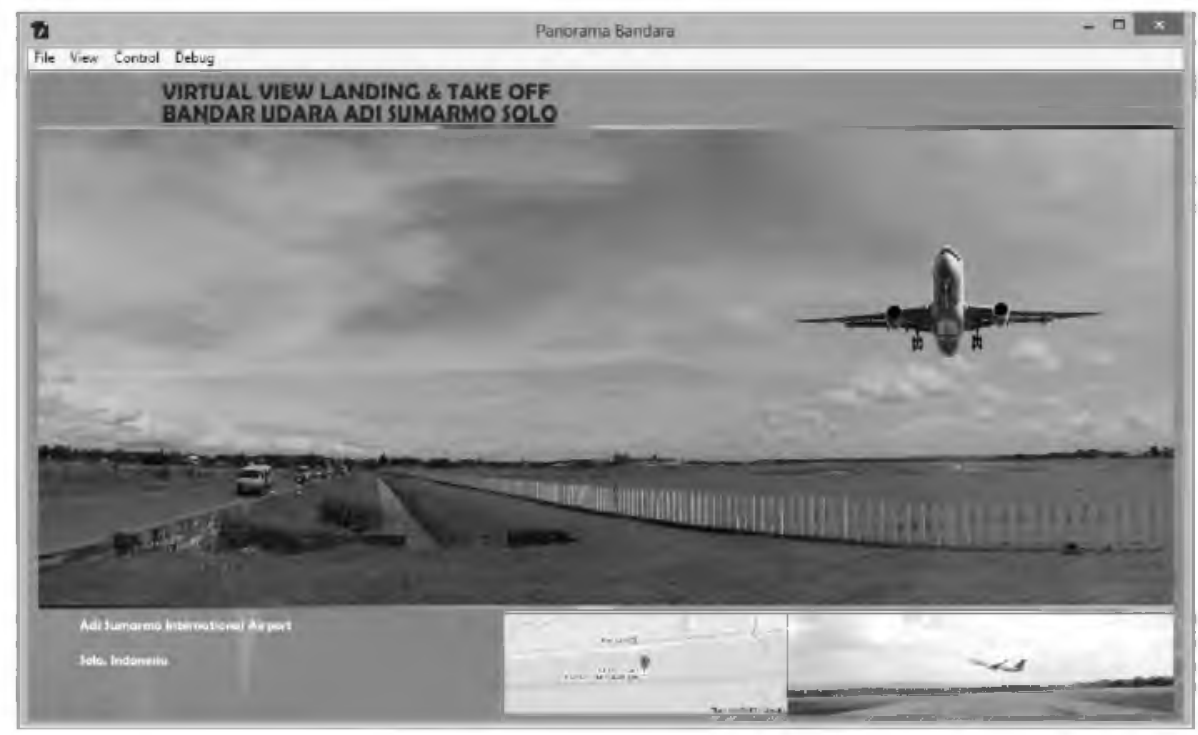

Gambar 9. Uji Coba Sistem

\section{Kesimpulan dan Saran}

\subsection{Kesimpulan}

1. Penerapan virtual view pada landing\&take off pesawat dapat menampilkan sebuah objek foto atau gambar dengan sudut pandangan yang lebih luas.

2. Dari hasil penelitian mengenai aplikasi ini adalah baik dan menarik penggunanya.

3. Sehingga dapat disimpulkan bahwa aplikasi dapat digunakan untuk membantu penggunanya untuk merencanakan informasi gambaran atau kondisi situasi sekeliling landing \& take off pesawat menggunakan panorama photo dan dapat ditampilkan pada media interaktif, website atau iklan display. 


\subsection{Saran}

1. Aplikasi ini dapat dikembangkan sebagai media informasi publik.

2. Aplikasi ini dapat dikembangkan untuk berbagai media audio visual dan tidak hanya dalam berbasis interaktif atau website.

\section{Daftar Pustaka}

Cahayani, Anisa, 2015, Rancang Bangun Virtual Tour Memorial Jendral H.M Soeharto Yogyakarta, AMIKOM, Yogyakarta.

Duff, John M \& Mohler, James L, 1997, Desain Grafik dan Halaman Web, Elex Media Komputindo, Jakarta.

Jogiyanto, H.M., 2001, Analisis \& Desain Sistem Informasi : Pendekatan Terstruktur Teori dan Praktek Aplikasi Bisnis, Penerbit ANDI, Yogyakarta.

McLeod, Jr. Raymond, 1995, Sistem Informasi Manajemen : Studi Sistem Informasi Berbasis Komputer. PT Bhuana Ilmu Popular.

Radion, Kristo, 2012, Easy Game Programming Using Flash and ActionScript 3.0.,Penerbit ANDI, Yogyakarta.

Suyanto, M, 2004, Analisis \& Desain Aplikasi Multimedia Untuk Pemasaran, Penerbit ANDI, Yogyakarta. 
Nurcahyani Dewi Retnowati, Muhammad Zainal Muttaqin 